\section{Draft Genome Resources for the Phytopathogenic Fungi Monilinia fructicola, M. fructigena, M. polystroma, and $M$. laxa, the Causal Agents of Brown Rot}

\author{
Yazmín Rivera, ${ }^{1, \dagger}$ Kurt Zeller, ${ }^{1}$ Subodh Srivastava, ${ }^{1,2}$ Jeremy Sutherland, ${ }^{1,2}$ Marco Galvez, ${ }^{1,2}$ \\ Mark Nakhla, ${ }^{1}$ Anna Poniatowska, ${ }^{3}$ Guido Schnabel, ${ }^{4}$ George Sundin, ${ }^{5}$ and Z. Gloria Abad ${ }^{1}$ \\ ${ }^{1}$ U.S. Department of Agriculture-Animal and Plant Health Inspection Service-Plant Protection and \\ Quarantine, Center for Plant Health Science and Technology-Beltsville Laboratory, Beltsville, MD 20705 \\ ${ }^{2}$ Department of Plant Pathology, North Carolina State University, Raleigh 27695 \\ ${ }^{3}$ Department of Phytopathology, Research Institute of Horticulture in Skierniewice, 96-100 Skierniewice, \\ Poland \\ ${ }^{4}$ School of Agricultural, Forest, and Environmental Sciences, Clemson University, Clemson, SC 29631 and \\ ${ }^{5}$ Department of Plant, Soil and Microbial Sciences, Michigan State University, East Lansing 48824.
}

\begin{abstract}
Fungi in the genus Monilinia cause brown rot disease of stone and pome fruits. Here, we report the draft genome assemblies of four important phytopathogenic species: $M$. fructicola, M. fructigena, M. polystroma, and M. laxa. The draft genome assemblies were $39 \mathrm{Mb}$ (M. fructigena), $42 \mathrm{Mb}$ ( $M$. laxa), $43 \mathrm{Mb}$ ( $M$. fructicola), and $45 \mathrm{Mb}$ (M. polystroma) with as few as 550 contigs ( $M$. laxa). These are the first draft genome resources publicly available for M. laxa, M. fructigena, and M. polystroma.
\end{abstract}

Monilinia fructicola, M. fructigena, M. polystroma, and M. laxa cause brown rot of stone (e.g., peach, nectarine, cherry, and plum) and some pome (apple and pear) fruits. These fungi can cause twig and blossom blights, as well as economically important fruit rot as the fruit ripen and their sugar content increases. M. fructicola and $M$. laxa are established within the United States, but $M$. fructigena and $M$. polystroma are currently not known from this country. Diagnostic methods for phytosanitary purposes need to be quick and reliable. Morphological similarity among these species and their overlapping host ranges can make differentiation between native and exotic species problematic and time-consuming. Whole-genome sequences of these four important pathogenic species will allow researchers to perform comparative genomic analysis to aid in the development of diagnostic markers to discriminate among them. In this study, we performed whole-genome sequencing and de novo assemblies of these four Monilinia species of interest.

We cultured all Monilinia isolates (Table 1) in potato dextrose broth for 4 to 6 days at $22 \pm$ $2^{\circ} \mathrm{C}$ on a rotary shaker at $120 \mathrm{rpm}$ and harvested mycelia by filtration. We cryogenically pulverized mycelia and isolated genomic DNA using a CTAB method modified from that in Porebski et al. (1997). PCR amplification of the internal transcribed spacer (ITS) and BLAST comparison confirmed the species identity for all four fungal cultures. Genomic DNA libraries were constructed using the TruSeq Nano Library Prep Kit (NeoPrep for M. fructigena and M. laxa) and per the protocol provided by Illumina for M. fructicola and M. polystroma. All libraries were quantified with a Qubit version 3.0 fluorometer (Life Technologies). Library quality was evaluated using the Agilent Genomic ScreenTape Assay (Agilent Technologies). All

\section{${ }^{\dagger}$ Corresponding author: Y. Rivera; E-mail: yazmin.rivera @aphis.usda.gov}

Mention of trade names or commercial products in this publication is solely for the purpose of providing specific information and does not imply recommendation or endorsement by the U.S. Department of Agriculture. The USDA is an equal opportunity provider and employer.

Accepted for publication 25 April 2018.

This article is in the public domain and not copyrightable. It may be freely reprinted with customary crediting of the source. The American Phytopathological Society, 2018.

\section{Funding}

This work was supported by the Animal and Plant Health Inspection Service Farm Bill Section 10007, Award number 03026800.

Additional keyword mycology 
Table 1. Isolate information and draft genome assembly summary statistics for Monilinia spp.

\begin{tabular}{|c|c|c|c|c|c|c|c|c|c|c|c|}
\hline Species & $\begin{array}{c}\text { Isolate } \\
\text { name }\end{array}$ & Origin & Year & Provided by & Read count & $\begin{array}{l}\text { Number of } \\
\text { contigs }\end{array}$ & $\begin{array}{l}\text { Maximum } \\
\text { scaffold } \\
\text { length (bp) }\end{array}$ & N50 & $\begin{array}{l}\text { Genome } \\
\text { coverage }\end{array}$ & $\begin{array}{c}\text { GC } \\
\text { content } \\
(\%)\end{array}$ & $\begin{array}{c}\text { Total } \\
\text { length (bp) }\end{array}$ \\
\hline M. fructicola & BR-32 & $\begin{array}{l}\text { Peach, Berrien } \\
\text { Co., Ml }\end{array}$ & 2009 & Sundin & $42,408,212$ & 2,350 & 414,517 & 66,420 & $296 x$ & 41.92 & $42,827,339$ \\
\hline M. fructigena & Mfg-5-SP-A & Apple, Hungary & 2009 & Schnabel & $20,423,570$ & 1,635 & 260,257 & 56,695 & $157 x$ & 41.90 & $39,335,235$ \\
\hline M. laxa & EBR Ba11b & $\begin{array}{l}\text { Cherry, Niagara, } \\
\text { NY }\end{array}$ & 2008 & Schnabel & $6,455,926$ & 550 & 673,002 & 159,077 & $46 x$ & 40.28 & $41,849,271$ \\
\hline M. polystroma & SP-61 & $\begin{array}{l}\text { Plum, } \\
\text { Skierniewice, } \\
\text { Poland }\end{array}$ & 2010 & Poniatowska & $34,783,998$ & 1,189 & 621,141 & 140,651 & $232 x$ & 39.27 & $44,639,555$ \\
\hline
\end{tabular}

libraries were sequenced on a MiSeq (Illumina) using a MiSeq version 3.0 reagent kit (300-bp x 2). Paired-end reads were checked for quality using FASTQC (Andrews 2016) before and after trimming adapters in CLC Workbench (CLC Genomics Workbench 10.1.1 https://www.qiagenbioinformatics.com/). Reads were de novo assembled using CLC Workbench. The total number of reads ranged from 6 to 42 million and were assembled in as little as 550-contigs for the $M$. laxa genome and up to 2,350-contigs for the $M$. fructicola genome (Table 1). Genome assembly completeness using the benchmarking universal single-copy orthologs (BUSCO) was estimated to be 97 to $98 \%$ for all four species (http://busco.ezlab.org) (Simão et al. 2015). Genome coverage for $M$. fructicola, M. fructigena, and M. polystroma was over 150x while only $46 \times$ for $M$. laxa. Draft genome assemblies are estimated between $39 \mathrm{Mb}$ ( $M$. fructigena) to $45 \mathrm{Mb}$ (M. polystroma). These genome assemblies are of comparable size to other published genomes in the family Sclerotiniaceae (e.g., Sclerotinia sclerotiorum 38.8 Mb [Derbyshire et al. 2017] and Botrytis cinerea 42.6 Mb [Van Kan et al. 2017], and most recently a different strain of M. fructicola 44.6 Mb [NGKE01000001] and M. aucupariae 54.9 Mb [NGKF01000001]).

The genomic resources reported here expand our molecular knowledge of Monilinia spp. and make it possible to conduct comparative genomics studies to identify species-specific gene targets and genetic variants for better diagnostic tools.

Accession numbers. This whole-genome shotgun project has been deposited at GenBank under the accession numbers PDME00000000 (M. fructicola), PDMD00000000 (M. fructigena), PDMC00000000 (M. polystroma), and PDUE00000000 ( $M$. laxa). The raw data for this experiment have been submitted to NCBI with SRA study SRP121347. Voucher specimens have been submitted to the U.S. National Fungus Collections under BPI910582 (M. polystroma), BPI910583 (M. fructigena), BPI910584 (M. laxa), and BPI910585 (M. fructicola).

\section{Acknowledgments}

We thank J. A. Crouch (USDA-ARS) for equipment support during the initial stages of sequencing and library preparation. We are also grateful to S. Haymes (USDA-APHIS-PPQ CPHST) for her groundwork in acquiring the Monilinia isolates needed in order to carry out this work.

\section{Literature Cited}

Andrews, S. 2016. FastQC: A quality control tool for high throughput sequence data. http://www.bioinformatics.babraham.ac.uk/projects/fastqc

Derbyshire, M., Denton-Giles, M., Hegedus, D., Seifbarghy, S., Rollins, J., Van Kan, J., Seidl, M. F., Faino, L., Mbengue, M., Navaud, O., Raffaele, S., HammondKosack, K., Heard, S., and Oliver, R. 2017. The complete genome sequence of the phytopathogenic fungus Sclerotinia sclerotiorum reveals insights into the genome architecture of broad host range pathogens. Genome Biol. Evol. 9: 593-618.
Porebski, S., Bailey, L. G., and Baum, B. R. 1997. Modification of a CTAB DNA extraction protocol for plants containing high polysaccharide and polyphenol components. Plant Mol. Biol. Report. 15:8-15.

Simão, F. A., Waterhouse, R. M., loannidis, P., Kriventseva, E. V., and Zdobnov, E. M. 2015. BUSCO: Assessing genome assembly and annotation completeness with single-copy orthologs. Bioinformatics 31:3210-3212.

Van Kan, J. A. L., Stassen, J. H. M., Mosbach, A., Van Der Lee, T. A. J., Faino, L., Farmer, A. D., Papasotiriou, D. G., Zhou, S., Seidl, M. F., Cottam, E., Edel, D., Hahn, M., Schwartz, D. C., Dietrich, R. A., Widdison, S., and Scalliet, G. 2017. A gapless genome sequence of the fungus Botrytis cinerea. Mol. Plant Pathol. 18:75-89. 